\title{
JPSE
}

(Journal of Physical Science and Engineering)

\begin{tabular}{l}
\hline Received \\
16 December 2020 \\
Revised \\
27 May 2021 \\
Accepted for Publication \\
21 June 2021 \\
Published \\
22 June 2021
\end{tabular}

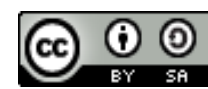

This work is licensed under a Creative Commons AttributionShareAlike 4.0 International License

\section{Study of Surface Morphology and Porosity of Composite Scaffold Nanofiber PVA/CS/HA with Electrospinning Method}

\author{
Hartatiek, Nasikhudin, A A D Putra, and Yudyanto* \\ Department of Physics, Faculty of Mathematics and Natural Sciences, Universitas Negeri Malang, \\ Jl. Semarang 5, Malang, 65145, Indonesia. \\ *E-mail: yudyanto.fmipa@um.ac.id
}

\begin{abstract}
This research aims to compose nanofibers as a scaffold material in bone tissue engineering in terms of surface morphological properties and porosity. HA nanorod was prepared by the precipitation-ultrasonication method, while the PVA/CS/HA nanofiber composites were made by the electrospinning method using a static collector. HA was characterized by using XRD and SEM-EDX, while the PVA/CS/HA nanofiber composites used FTIR and SEM. The results show that HA nanorod has a crystalline size of $10.86 \mathrm{~nm}$, crystallinity level of $52.38 \%$, and $\mathrm{Ca} / \mathrm{P}$ ratio of 1.70 . From the SEM image shows HA nanorod width of $11.6 \mathrm{~nm}$ and $97.53 \mathrm{~nm}$ in length and some of it still in the form of HA nanoparticles. The diameter and porosity of PVA/CS/HA nanofiber with addition of $0 \%$, $10 \%, 20 \%$ HA were $275,212,265 \mathrm{~nm}$ and $72.94,69.49,70.81 \%$, respectively.

Keywords: Hydroxyapatite, PVA, chitosan, electrospinning.
\end{abstract}

\section{Introduction}

For more than a decade, the traditional methods of autograft and allograft bone grafts have been used to treat large-scale bone defects. These method is used of grafting the patient's own bone whereas allograft is a method of grafting a donor bone from another person/body [1]. However, these techniques has disadvantages of high surgical risks, such as bleeding, inflammation, infection, chronic disease, and high cost [2]. Whereas allograft bone grafts are associated with the risk of immunoreaction, infectious transmission, and have a record high failure rate for long term use [3], [4].

Scaffold engineering of bone tissue appears as a solution that can provide support for newly formed bone tissue, as a temporary site for interactive cell traffic and for the formation of the extracellular matrix of bone [5]. Hydroxyapatite (HA) meets the requirements as a scaffold biomaterial with mineral components similar to natural bone and has osteoconductivity, bone tissue binding ability, biocompatibility, affinity for biopolymers, and high osteogenic potential [6], [7]. HA crystals found in bone are generally nanometer-shaped needles (nanorods) with a dimension range of $60 \mathrm{~nm}$ long and 5$20 \mathrm{~nm}$ wide [8].

Chitosan (CS) was chosen due to its various superior properties in medical and tissue engineering applications, including biodegradability, biocompatibility, non-toxic, hydrophilic, and anti-microbial properties [9], [10]. One of the modifications with synthetic polymer PVA is used to overcome the weakness of the properties of CS which is known to be difficult to form fibers. In addition, PVA also has several superior properties for application in the medical field, including biocompatibility, nontoxicity, non-carcinogenicity, bioadhesive, and good mechanical properties [11].

In this study, HA nanorod synthesis was carried out using the precipitation-ultrasonication method, then it was composited with the PVA/CS polymer matrix, and the process of forming nanofibers using the electrospinning method. The effect of HA addition on surface morphological properties and porosity in PVA/CS/HA nanofiber composites was observed because in nanofiber scaffolds, these parameters have an important role in providing space for cell regeneration as a place to interact and form new tissue [12]. 


\section{Method}

\subsection{Synthesis of Hydroxyapatite}

The synthesis of HA nanorod was carried out by the precipitation-ultrasonication method. $\mathrm{KH}_{2} \mathrm{PO}_{4}$ solution $(0.19 \mathrm{M})$ was added dropwise to a solution of $\mathrm{Ca}\left(\mathrm{NO}_{3}\right)_{2}(0.32 \mathrm{M})$, stirred using a magnetic stirrer for 60 minutes at $80{ }^{\circ} \mathrm{C}$, rotation speed of $600 \mathrm{rpm}$, and the reaction $\mathrm{pH}$ was maintained at $\mathrm{pH} 9$ using $\mathrm{NH}_{4} \mathrm{OH}$ solution $(0.25 \mathrm{M})$ with the following Equation (1).

$$
\left[\begin{array}{c}
10 \mathrm{Ca}\left(\mathrm{NO}_{3}\right)_{2(\mathrm{aq})}+6 \mathrm{KH}_{2} \mathrm{PO}_{4(\mathrm{aq})} \\
+20 \mathrm{NH}_{4} \mathrm{OH}_{(\mathrm{aq})}
\end{array}\right] \rightarrow\left[\begin{array}{c}
\mathrm{Ca}_{10}\left(\mathrm{PO}_{4}\right)_{6}(\mathrm{OH})_{2(\mathrm{~s})}+6 \mathrm{KOH}_{(\mathrm{aq})} \\
+20 \mathrm{NH}_{4} \mathrm{NO}_{3(\mathrm{aq})}+12 \mathrm{H}_{2} \mathrm{O}_{(\mathrm{l})}
\end{array}\right]
$$

The solution obtained was sonicated for 30 minutes at $50{ }^{\circ} \mathrm{C}$ with ultrasonicator frequency of $45 \mathrm{kHz}$. Then the solution was precipitated using centrifugation at 2,200 rpm for 10 minutes. The precipitate was taken and washed with DI water, then dried at $110{ }^{\circ} \mathrm{C}$ for 5 hours. The sample is ready to XRD characterization process to determine the purity of the phase, crystal grain size, and crystallinity. SEM EDX to determine the structure and $\mathrm{Ca} / \mathrm{P}$ ratio of the sample.

\subsection{Synthesis of PVA/CS/HA Nanofiber Composite}

Dissolve 0.52 grams of PVA powder in $4 \mathrm{ml}$ of distilled water using a magnetic stirrer at a speed of 700 $\mathrm{rpm}$ and a temperature of $110{ }^{\circ} \mathrm{C}$ for 3 hours. Dissolving 0.1 gram of chitosan in $5 \mathrm{ml}$ of $2 \%$ acetic acid using a magnetic stirrer at a speed of $700 \mathrm{rpm}$ and room temperature for 3 hours. The homogeneous dissolved PVA was added with chitosan and stirrer at a speed of $700 \mathrm{rpm}$ and a temperature of $110^{\circ} \mathrm{C}$ for 2 hours until it was homogeneous. Adding 10 and 20\% HA powder to PVA/CS solution of 0.054 and 0.108 grams respectively and stirrer at $700 \mathrm{rpm}$ and $110^{\circ} \mathrm{C}$ for 2 hours. The solution was sonicated for 30 minutes and then electrospinning with a needle to collector distance of $16.5 \mathrm{~cm}$, an electrospinning voltage of $12 \mathrm{kV}$, and a flowrate of $80 \mathrm{ml} /$ minute for 90 minutes. Make initial observations using an optical microscope to see the formation of nanofibers. The PVA/CS/HA composites were then characterization by FTIR and SEM.

\section{Result and Discussion}

\subsection{Analysis XRD of Hydroxyapatite}

Figure 1 shows the XRD HA diffraction pattern of fitting results using Rietica software with a comparison database derived from Crystallography Open Database (COD) number 9013627 to determine the lattice parameters, crystal structure, and size of HA nanoparticles. Where the model has a lattice value $\mathrm{a}=\mathrm{b}=9.4081 \AA$ and $\mathrm{c}=6.8887 \AA$ with a value of $\mathrm{a}=\mathrm{b} \neq \mathrm{c} ; \alpha=\beta=90^{\circ} ; \gamma=120^{\circ}$ which indicates that hydroxyapatite has a hexagonal crystal structure. The average value of the crystal size resulting from the refinement of the HA sample was $10.86 \mathrm{~nm}$. Whereas in a study conducted by Mehta et al. [16] using the same method produced an average crystal size of $36.51 \mathrm{~nm}$ and found that giving temperature treatment by sintering could increase the crystal size of hydroxyapatite nanorod.

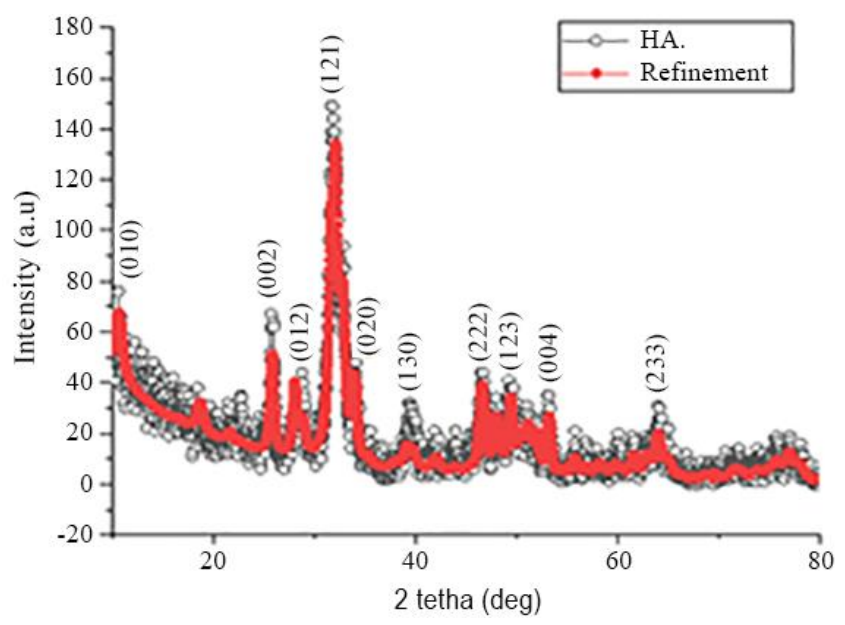

Figure 1. Refinement hydroxyapatite XRD pattern. 
The degree of crystallinity from the XRD test results in this study is calculated using Equation 2.

$$
\chi_{c}=\frac{\text { Area Fraction of Crystal }}{\text { Area Fraction of Crystal }+ \text { Area Fraction of Amorf }} \times 100 \%
$$

From the calculation using this formula, the degree of crystallinity of the HA synthesized results is $52.38 \%$. This value fulfills the crystallinity level that must be met in the body, which is around 40 $60 \%$. ISO standardized specifications (ISO 13779-1:2000) state that to make HA coatings that have sufficient mechanical strength, at least they must have a degree of crystallinity of more than $45 \%$. This shows that the results of the synthesis of this hydroxyapatite sample have met the minimum crystallinity level of the given ISO standard. In previous studies proved that the degree of crystallinity of hydroxyapatite can be increased with increasing reaction temperature [13]-[16].

\subsection{Analysis SEM-EDX of Hydroxyapatite}

Preparation of hydroxyapatite nanorod using the precipitation-ultrasonication method in this study produced hydroxyapatite in the form of partially agglomerated nanoparticles (see Figure 2). The length and width dimensions of the measurement results using ImageJ software obtained an average nanorod length of $97.53 \mathrm{~nm}$ and a width of $11.67 \mathrm{~nm}$.

The results of the elemental analysis from the SEM-EDX characterization in Figure 3 show that the $\mathrm{Ca} / \mathrm{P}$ value in the hydroxyapatite sample in this study through the calculation of the elemental mass ratio is 1.70 . This result is close to the mass ratio of $\mathrm{Ca} / \mathrm{P}$ hydroxyapatite in natural bone which is 1.67 [17] which gives it superior mechanical properties [18], [19].

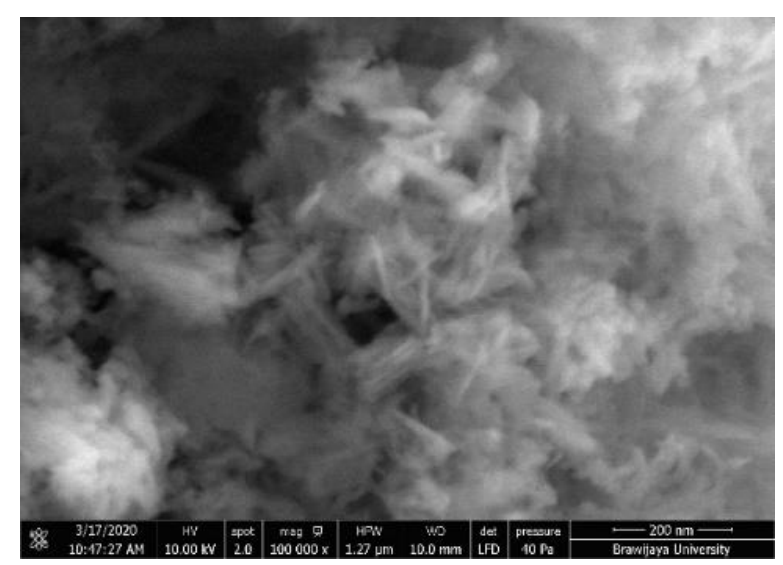

(a)

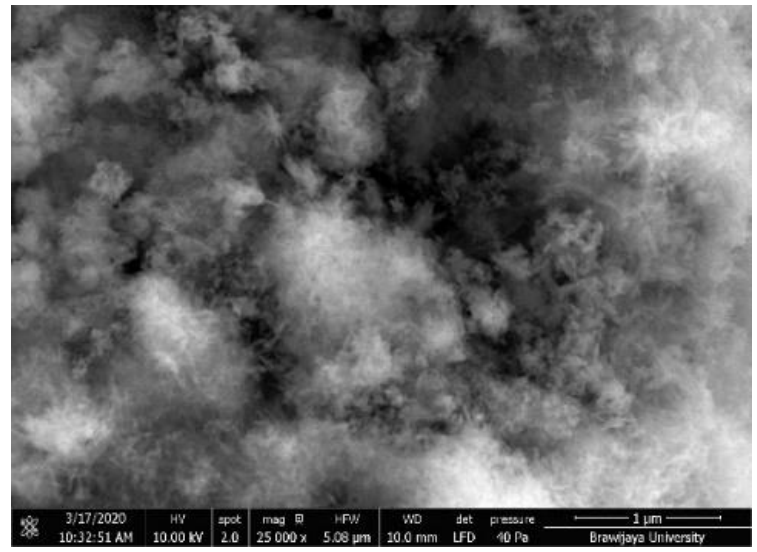

(b)

Figure 2. The results of SEM characterization of HA samples with magnification (a) 100,000 times; (b) 25,000 times.

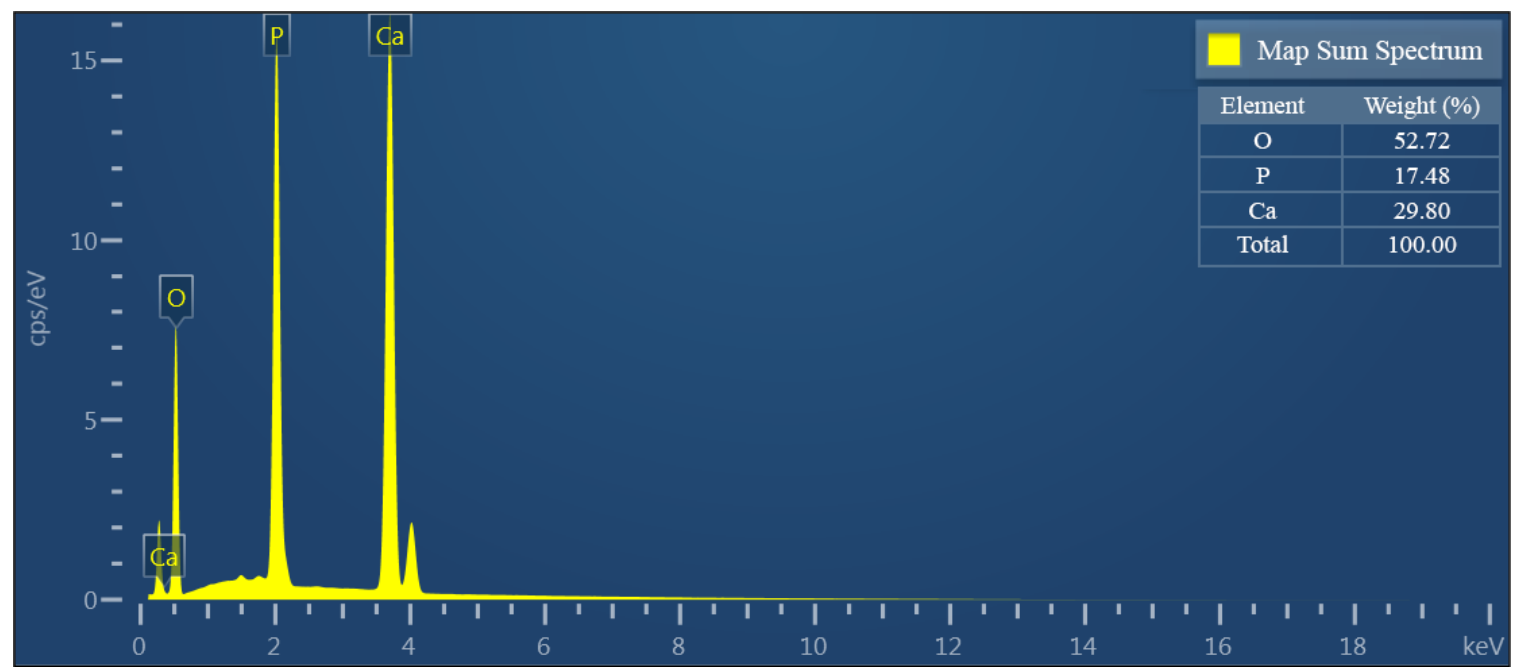

Figure 3. SEM EDX hydroxyapatite results. 


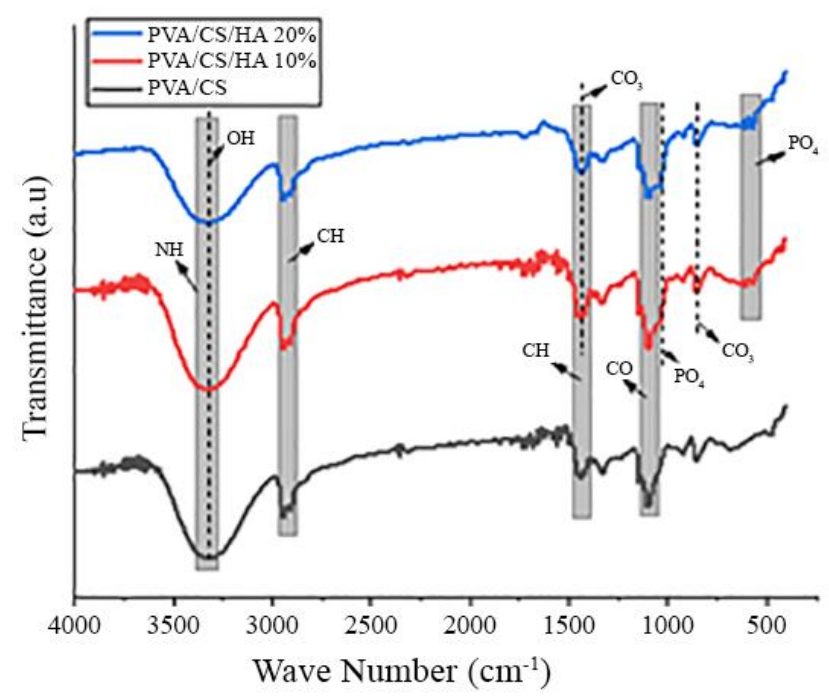

Figure 4. FTIR spectrum of PVA/CS (grey line), PVA/CS/HA 10\% (red line), and PVA/CS/HA 20\% (blue line).

\subsection{Analysis FTIR of PVA/CS/HA Nanofiber Composite}

The FTIR test results in Figure 4, sample A1 (presented by grey line) shows the presence of PVA with the detection of the $\mathrm{CH}$ bending, $\mathrm{CO}$ stretching, and $\mathrm{OH}$ stretching functional groups at wave numbers around 1,$435 ; 1,095$; and $3,315 \mathrm{~cm}^{-1}$, respectively. The presence of chitosan with the appearance of the amide $(\mathrm{NH})$ and amino $(\mathrm{CH})$ functional groups at wave numbers 3,315 and $2,941 \mathrm{~cm}^{-1}$. From these results show the increasing HA concentration causes the hydroxyl $(\mathrm{OH})$ functional group in sample A2 (presented by red line) shift to the left (bigger) than sample A1 from 3,315 to $3,331 \mathrm{~cm}^{-1}$. This suggests that a stronger hydrogen bond is formed due to the increase in $\mathrm{OH}$ from the addition of hydroxyapatite [20]. In the A3 (presented by blue line) sample the hydroxyl group shifted back to a smaller wave number at $3,315 \mathrm{~cm}^{-1}$ which reflects the agglomeration of HA. The agglomeration that occurs will reduce the interaction between the surface of the HA nanoparticles and the polymer, so that the active $\mathrm{OH}$ groups on the surface of the two materials will have less opportunity to interact with each other [21].

\subsection{Analysis SEM of PVA/CS/HA Nanofiber Composite}

Figure 5(a) shows that the surface morphology of the PVA/CS matrix produces fibers that are quite homogeneous, continuous, and without beads. This shows that the PVA/CS composite has dissolved well and the electrospinning parameters (needle to collector distance, voltage, and flowrate) are appropriate. Figure $5(\mathrm{~b})$ shows the addition of $10 \%$ HA to produce a homogeneous, continuous fiber, and there are few beads due to the agglomerated HA. Whereas in Figure 5(c) the addition of 20\% HA shows less homogeneous fibers, almost broken, and there are many beads with micron-sized agglomerations that can cause the scaffold to underperform in cell adhesion and proliferation [22].

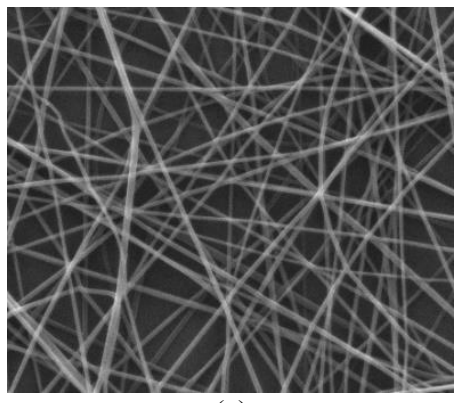

(a)

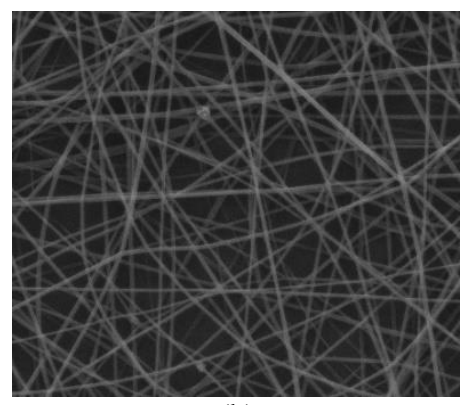

(b)

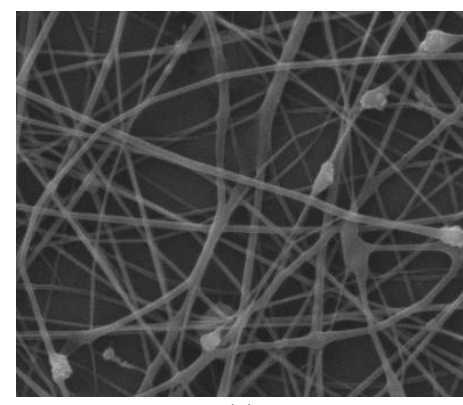

(c)

Figure 5. SEM characterization results at magnification of 10,000 times nanofiber (a) PVA/CS, (b) PVA/CS/HA 10\%, and (c) PVA/CS/HA $20 \%$. 


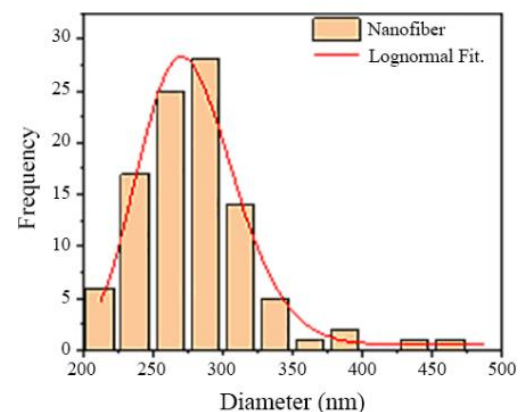

(a)

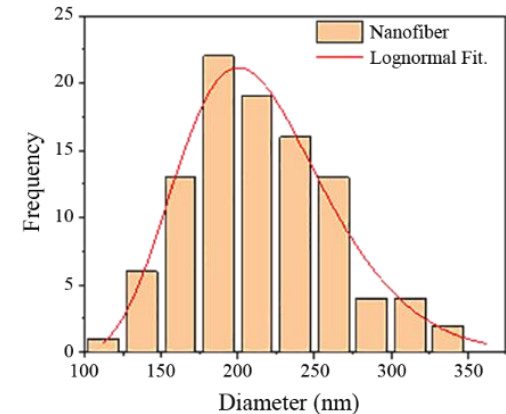

(b)

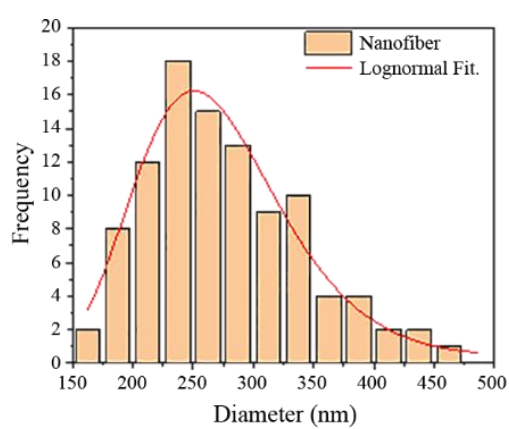

(c)

Figure 6. Nanofiber diameter distribution of (a) PVA/CS, (b) PVA/CS/HA 10\%, and (c) PVA/CS/HA 20\%.

Table 1. Porosity and diameter distribution of PVA/CS/HA nanofibers.

\begin{tabular}{lccc}
\hline & Porosity (\%) & $\begin{array}{c}\text { Fiber Diameter } \\
\text { Distribution }(\mathrm{nm})\end{array}$ & $\begin{array}{c}\text { Fiber Average } \\
\text { Diameter (nm) }\end{array}$ \\
\hline PVA/CS & 72.94 & $204-457$ & $(274.94 \pm 1.90)$ \\
\hline PVA/CS/HA 10\% & 69.49 & $118-340$ & $(211.77 \pm 3.60)$ \\
\hline PVA/CS/HA 20\% & 70.81 & $160-456$ & $(264.99 \pm 4.71)$ \\
\hline
\end{tabular}

The fiber diameter distribution is shown in Figure 6 that the level of homogeneity of the fiber diameter size decreases with the addition of HA. The average diameter size of PVA/CS/HA fibers decreased in the nanofiber composites without HA to the addition of $10 \%$ HA. The smaller size of the fiber diameter is due to the increased viscosity of the solution with the addition of HA [23]. Meanwhile, the addition of $20 \% \mathrm{HA}$ indicates that the fiber diameter increases again due to a lot of HA agglomeration which causes the HA interaction with the PVA/CS matrix to be disturbed so that when the fiber formation becomes unstable which results in the formation of beads and the fiber diameter size is not homogeneous. Natural bone tissue itself has organic matrix fibers that range in diameter from 100 to $450 \mathrm{~nm}$ [24].

Table 1 shows the results of the porosity and fiber diameter which shows a unidirectional relationship. This happens because the simple porosity calculation using OriginPro software depends on the SEM test results' surface area and fiber thickness. The PVA/CS/HA $10 \%$ composite, which shows a smaller fiber diameter, causes a smaller surface area and a larger pile of fibers. Thicker than the addition of HA 0 and $20 \%$ resulted in less porosity. The greater the porosity the greater the size of the fiber diameter, and vice versa, the smaller the porosity, the smaller the fiber diameter size [23]. The tendency for fibers to accumulate will result in poor porosity and reduced pore size [25].

\section{Conclusion}

The synthesized hydroxyapatite has a hexagonal crystal structure, a crystal size of $10.86 \mathrm{~nm}$ and a crystallinity level of $52.38 \%$ with a $\mathrm{Ca} / \mathrm{P}$ ratio close to the ideal value of HA (1.67), which is 1.70 . HA nanorod has been successfully synthesized with dimensions of $97.53 \mathrm{~nm}$ in length and $11.67 \mathrm{~nm}$ in width with part of it in the form of HA nanoparticles. The addition of HA concentrations in the $\mathrm{PVA} / \mathrm{CS} / \mathrm{HA}$ nanofiber composites can reduce the size of the fiber diameter thereby increasing the surface area of the fiber. In the other hand the addition of highest HA concentration affected in reduced fiber homogeneity, nearly cut fibers, HA agglomeration, and the formation of beads. The porosity of the PVA/CS/HA nanofiber composites has a direct relationship with the average fiber diameter and is inversely related to the thickness of the nanofiber.

\section{Acknowledgment}

This research was supported by Kemenristek Dikti through PNBP funds from the Universitas Negeri Malang 2020. 


\section{References}

[1] Y. Yudyanto, Y. D. Sugara, and H. Hartatiek, "Pengaruh nanosilika terhadap kekerasan dan porositas nanokomposit HA-SiO2 berbasis batuan onyx Bojonegoro," JPSE (J. Phys. Sci. Eng.), vol. 1, no. 1, pp. 13-18, 2016.

[2] H. J. Haugen, S. P. Lyngstadaas, F. Rossi, and G. Perale, "Bone grafts: Which is the ideal biomaterial?," J. Clin. Periodontol., voo. 46, pp. 92-102, 2019.

[3] G. F. de-Grado et al., "Bone substitutes: A review of their characteristics, clinical use, and perspectives for large bone defects management," J. Tissue Eng., vol. 9. pp. 1-18, 2018.

[4] T. Winkler, F. A. Sass, G. N. Duda, and K. Schmidt-Bleek, "A review of biomaterials in bone defect healing, remaining shortcomings and future opportunities for bone tissue engineering: The unsolved challenge," Bone and Joint Res., vol. 7, no. 3. pp. 232-243, 2018.

[5] F. M. Chen and X. Liu, "Advancing biomaterials of human origin for tissue engineering," Prog. Polym. Sci., vol. 53, pp. 86-168, 2016.

[6] A. S. Motamedi, H. Mirzadeh, F. Hajiesmaeilbaigi, S. Bagheri-Khoulenjani, and M. Shokrgozar, "Effect of electrospinning parameters on morphological properties of PVDF nanofibrous scaffolds," Prog. Biomater., vol. 6, no. 3, pp. 113-123, 2017.

[7] B. Dhandayuthapani, Y. Yoshida, T. Maekawa, and D. S. Kumar, "Polymeric scaffolds in tissue engineering application: A review," Int. J. Polym. Sci., vol. 2011, pp. 1-19, 2011.

[8] M. Sadat-Shojai, M. T. Khorasani, E. Dinpanah-Khoshdargi, and A. Jamshidi, "Synthesis methods for nanosized hydroxyapatite with diverse structures," Acta Biomater., vol. 9, no. 8, pp. 7591-7621, 2013.

[9] U. Vijayalakshmi, "Preparation of Ag doped hydroxyapatite-Fe3O4-chitosan composites: In vitro biocompatibility study on MG-63 cells for orthopedic applications," Adv. Sci. Lett., vol. 24, no. 8, pp. 5901-5906, 2017.

[10] W. Damayanti, E. Rochima, and Z. Hasan, "Application of chitosan as antibacterial for pangasius fillet at low temperature storage," J. Pengolah. Has. Perikan. Indones., vol. 19, no. 3, pp. 321328, 2017.

[11] U. Anjaneyulu, B. Priyadarshini, A. N. Grace, and U. Vijayalakshmi, "Fabrication and characterization of $\mathrm{Ag}$ doped hydroxyapatite-polyvinyl alcohol composite nano fibers and its in vitro biological evaluations for bone tissue engineering applications," J. Sol-Gel Sci. Technol., vol. 81, no. 3, pp. 750-761, 2016.

[12] F. Sun, H. Zhou, and J. Lee, "Various preparation methods of highly porous hydroxyapatite/polymer nanoscale biocomposites for bone regeneration," Acta Biomaterialia, vol. 7, no. 11. pp. 3813-3828, 2011.

[13] M. A. H. Margareta, A. Fuad, S. A. Ilmiawati, and S. Wonorahardjo, "Sintesa hydroxyapatite (Ca10(PO4)6(OH)2) berbasis batu kapur," J. Peneliti. Fis. Aplikasinya (JPFA), vol. 5, no. 1, pp. 15-20, 2015.

[14] M. Lubis, M. H. S. Ginting, N. F. Dalimunthe, D. M. T. Hasibuan, and S. Sastrodihardjo, "The influence of chicken egg shell as fillers on biocomposite acrylic resin for denture based," in IOP Conf. Ser.: Mater. Sci. Eng., vol. 180, no. 1, 2017, p. 012008.

[15] B. Riyanto and A. Maddu, "Material of hydroxyapatite-based bioceramics from tuna fishbone," J. Pengolah. Has. Perikan. Indones., vol. 16, no. 2, pp. 119-132, 2014.

[16] D. Mehta, P. Mondal, V. K. Saharan, and S. George, "Synthesis of hydroxyapatite nanorods for application in water defluoridation and optimization of process variables: Advantage of ultrasonication with precipitation method over conventional method," Ultrason. Sonochem., vol. 37, pp. 56-70, 2017.

[17] M. Rana, N. Akhtar, S. Rahman, H. M. Jamil, and S. M. Asaduzzaman, "Extraction of hydroxyapatite from bovine and human cortical bone by thermal decomposition and effect of gamma radiation: A comparative study," Int. J. Complement. Altern. Med., vol. 8, no. 3, pp. 1$10,2017$.

[18] H. L. Jaber and T. A. Kovács, "Preparation and synthesis of hydroxyapatite bio-ceramic from bovine bone by thermal heat treatment," Epa. - J. Silic. Based Compos. Mater., vol. 71, no. 3, pp. 98-101, 2019.

[19] W. Habraken, P. Habibovic, M. Epple, and M. Bohner, "Calcium phosphates in biomedical applications: materials for the future?," Mater. Today, vol. 19, no. 2, pp. 69-87, 2016. 
[20] M. H. Alves, B. E. Jensen, A. A. Smith, and A. N. Zelikin, "Poly (vinyl alcohol) physical hydrogels: New vista on a long serving biomaterial," Macromolecular Biosci., vol. 11, no. 10, pp. 1293-1313, 2011.

[21] I. K. Januariyasa, I. D. Ana, and Y. Yusuf, "Nanofibrous poly(vinyl alcohol)/chitosan contained carbonated hydroxyapatite nanoparticles scaffold for bone tissue engineering," Mater. Sci. Eng. C, vol. 107, p. 110347, 2019.

[22] A. Hasan et al., "Electrospun scaffolds for tissue engineering of vascular grafts," Acta Biomater., vol. 10, no. 1, pp. 11-25, 2014.

[23] R. Stepanyan et al., "Nanofiber diameter in electrospinning of polymer solutions: Model and experiment," Polymer (Guildf)., vol. 97, pp. 428-439, 2016.

[24] X. Li et al., "Nanostructured scaffolds for bone tissue engineering," J. Biomed. Mater. Res. Part A, vol. 101, no. 8, pp. 2424-2435, 2013.

[25] S. Soliman et al., "Controlling the porosity of fibrous scaffolds by modulating the fiber diameter and packing density," J. Biomed. Mater. Res. Part A, vol. 96, no. 3, pp. 566-574, 2011. 